\title{
Construction of the Multimedia Teaching Platform of Cost Accounting Course Based on EXCEL VBA Program
}

\author{
https://doi.org/10.3991/ijet.v13i05.8436 \\ Zhiyong Zhang \\ Chongqing College of Finance and Economics, Chongqing, China \\ zhangzhiyong1011@sina.cn
}

\begin{abstract}
There exists some problems in domestic multimedia teaching of "Cost Accounting" courses such as the difficulties of achieving teaching objectives and teaching effect, slow control loading, data missing in excel saving page, data leakage risk, etc. This paper has constructed a multi-media teaching platform for "Cost Accounting" course based on Excel VBA technology. First, the paper has elaborated the theoretical foundation of constructing "Cost Accounting" course multimedia teaching platform. Then the paper has elaborated the methods and procedures of constructing "Cost Accounting" course multimedia teaching platform based on Excel VBA and displayed the construction results. In addition, it has innovatively applied the technology of webpage remote processing classroom in Excel. In the end, the paper has applied and verified the teaching effect of the platform in practical teaching. The result shows that the multi-media teaching platform constructed in this paper has greatly improved the teaching effect of "Cost Accounting" course.
\end{abstract}

Keywords-Excel VBA, “Cost Accounting”, multimedia teaching platform

\section{Introduction}

Multi-media teaching platform refers to comprehensive management and application of different information such as text, image, video, animation, data and sound by using computer's powerful computing and processing capability so as to provide comprehensive sensorial interaction for users [1]. Modern computer multimedia technology is characterized with diversified media types, high interaction and integration, and instantaneity. Multi-media technology if applied to assisted instruction process can display target knowledge and skills to students in a more abundant way compared with traditional teaching technologies, so as to improve teaching effect greatly. Excel with strong data processing function, and the advantages of easy and fast for students to learn, has been widely applied in many industries [2]. But there exist some defects in its functions. For example, data processing operation that requires multiplication can only be realized by using the low-efficiency tool record macro. Meanwhile, record macro cannot realize some data processing functions not provided by Excel. But VBA can seamlessly integrate to Excel software so as to realize more complicated functions [3]. At present, multimedia teaching based on Excel VBA technology has 
been widely used in courses requiring mass data analysis and processing such as Statistics, Finance [4] and Economics.

Cost Accounting as one of foundation courses of accounting teaching shows some disadvantages when conducting multimedia teaching in the course. First, regarding teaching contents, traditional multi-media technology combining graphs, texts and sound cannot realize the teaching objective and teaching effect [5]. Secondly, regarding teaching methods, traditional embedded Office control implementation model may result in slow loading speed for excel sheet containing big data volume and may lead to data missing if no response when saving excel sheet. Webpage Office exist the risk of data leakage. Thus, this paper will apply multimedia teaching technology based on Excel VBA in "Cost Accounting" course teaching and innovatively propose a technology of webpage remote processing classroom Excel.

\section{State of the art}

In the literature of this field, some works have proposed a project-based VBA multi-media technological teaching model applied in economics and management courses. Students are divided into different problem-solving teams in the project so as to improve students' practical ability by applying VBA to solve practical problems [6]. Apart from this, Liang et al. [7] have made in-depth research on cultivating students' computational thinking ability by applying Excel VBA multi-media technology and think introducing VBA can effectively practice students' thinking ability.

Some researches on the application of Excel VBA multi-media technology in teaching focus more on the advantages of VBA program design in cultivating students' specific ability. Tsai used Excel to construct an interactive environment to instruct statistics concepts to students. This environment has greatly reduced the difficulty of understanding and mastering intricate and obscure statistics concepts [8]. Fujioka has specifically researched the advantages of introducing Excel VBA to course teaching on improving students' problem-solving ability and proposed that VBA is easy to learn, and it can effectively practice students' ability of applying information technology for problem-solving. Compared with the existing researches of Excel VBA multi-media technology in teaching field, the research in this paper has two innovation points as follows:

During the teaching course of Cost Accounting, it requires to conduct comprehensive instruction of enterprise cost calculation and distribution method. Traditional courseware and blackboard can hardly display these contents clearly. Thus, the comprehensive modelling will be conducted for the process, calculation method and distribution rule involved in Cost Accounting based on Excel VBA so as to realize the basic principles and rules of Cost Accounting in Excel.

During the teaching process, if issuing Excel VBA documents to each student for instruction, teachers will not know students' current learning and operating status and cannot conduct target education. So, this paper has designed an integrated multimedia teaching platform based on Excel VBA program which can provide a front-end webpage for Excel VBA program based on JSP technology. In class, students can use 
this front-end webpage for Excel remote operating and processing. The backstage program will completely record and analyze students' operation so as to provide reference for carrying out teaching.

\section{Theoretical construction}

\subsection{Distribution method modelling and program design for Cost Accounting}

The main purpose of Excel VBA is to realize functions that Excel native program cannot achieve or possess through programming method. Excel VBA in Cost Accounting is mainly for data processing and analysis through VBA. But in specific program design process, it mainly involves basic concepts in three aspects: object, conditional judgment and circular process [9].

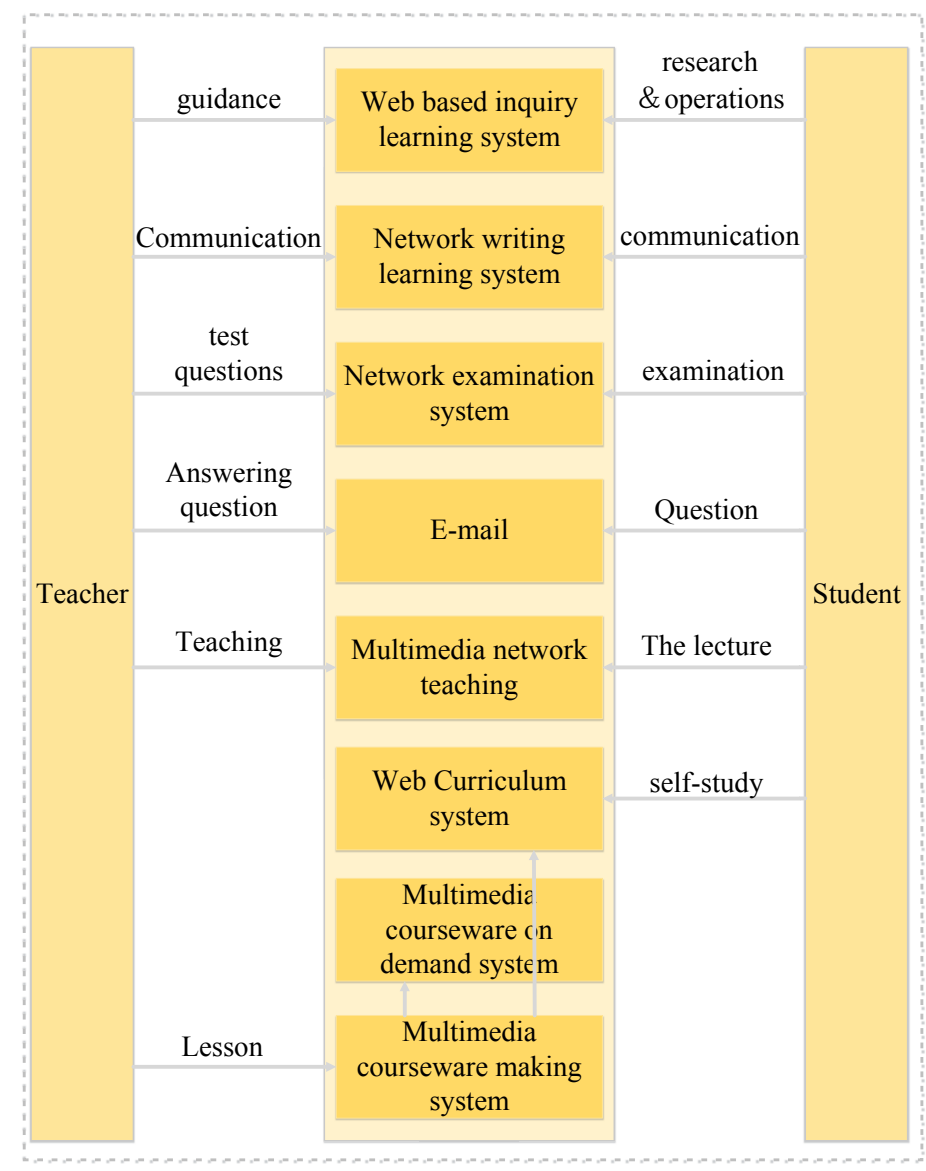

Fig. 1. A schematic diagram of the structure of the Excel VBA modeling system for cost accounting 
Object. In Excel VBA program, the object is the target for program processing. But excel in Cost Accounting mainly involves table cell or cell area processing. The cost data, calculation data in Cost Accounting will be stored in specific cells and be filled into specific target cell area after distribution and calculation. Applying object by effective means to specific position is the basis of program operation. The rule of referring table cells in Excel VBA is to formulate workbook, worksheet, and cell area in sequence to locate the object's position.

Conditional judgement. During the process of cost calculation and distribution in Cost Accounting, it requires to take different data processing methods in different cases. Excel VBA can support more than 256 layers conditional judgement operation. So, it can effectively support complex distribution and calculation theories and methods in Cost Accounting.

Circular process. Excel VBA provides three kinds of basic circular process logic structures, For-Each circulation, Do-While circulation and Do-Until circulation. The structures are much of a muchness in logics with the essence of implementing a segment program block repeatedly suitable for different calculation occasions. This paper has elaborated the circulation control structure of Excel VBA from For-Each structure, the lexeme of which is to implement the statement in the statement block for once for each element in the object set. This method has provided powerful support to implement the calculation principle of Cost Accounting.

\subsection{Excel files remote operation technology}

Excel Java language operation technology. Construct an implementation framework through front-end webpage for Excel operation based on JSP technology which is a front-end programming language based on Java enterprise level development technology. Students' input will finally convert into Java codes for operation. Thus, Java code can be used to operate Excel files. This paper has applied POI API issued by Apache Foundation. POI is a class lib completely operating Microsoft files providing a complete set of Excel operation toolkit. This technology can conveniently combine with front-end webpage to realize remote operation of Excel files. Graph 1 is the class and its description used during development process which can be used to operate Excel files through Java codes.

Table 1. Excel file operation class

\begin{tabular}{|l|l|l|}
\hline \multicolumn{1}{|c|}{ Model } & \multicolumn{1}{c|}{ Sorts } & \multicolumn{1}{c|}{ Description } \\
\hline org.apache.poi.hssf.usermodel & HSSFWorkbook & Excel workbook class \\
\hline \multirow{3}{*}{ org.apache.poi.ss.usermodel } & Workbook & Workbook model class \\
\cline { 2 - 4 } & Sheet & Worksheet model class \\
\cline { 2 - 3 } & Row & Each row corresponding class in worksheet \\
\cline { 2 - 3 } & Cell & Table cell class \\
\hline
\end{tabular}


Programming language inter-translation technology .VBA programming language issued together with the package of Microsoft Excel has been embedded in Excel software. So, users can directly call in Excel program with no need to configure programming environment in advance like other programming languages. Meanwhile VBA with easy syntax can implement most functions achieved by other languages. So, VBA is suitable for non-computer course teaching. But in multi-media system developed in this paper, the front-end webpage used by students are constructed by JSP technology and the final Excel file operation must be realized by Java program. So, VBA code must be translated into Java codes in this paper to realize remote processing excel files. The theoretical basis of this implementation is based on the fundamentals of compilation of high level programming language. During the process of converting high level programming language into machine language, all program blocks will produce relevant syntax tree and then to produce machine language code. Syntax tree, independent from specific programming language, is in one-to-one corresponding relation with different languages. Syntax tree can be used as the medium to realize the inter-translation between VBA program and Java program. Basic framework is shown in Fig 2.

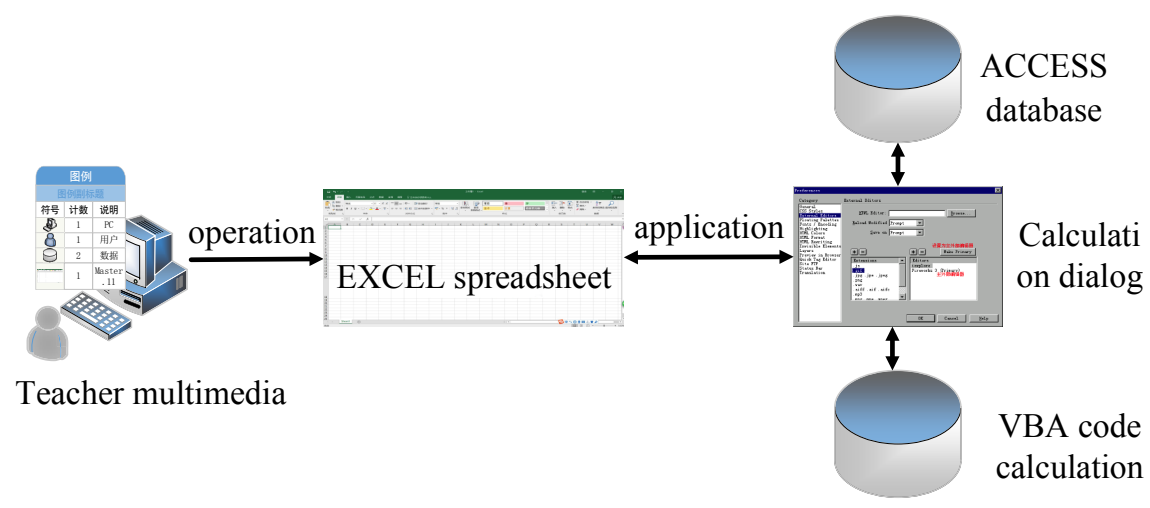

Fig. 2. Flow diagram of the inter-translation between VBA program and Java program

\section{Construction of Excel VBA program in multi-media teaching of Cost Accounting course}

Use modularized construction method to construct a multi-media teaching platform of Cost Accounting course based on Excel VBA program. Divide multi-media teaching platform into different modules by front-end, back-end and function, clearly define the functions to be fulfilled in each module, exterior interfaces provided and connection methods between different modules. Then develop these modules based on these definitions for module URL load after module construction so as to complete the construction of the whole multi-media teaching platform. The advantage of this construction method is that it can decompose complicated system by modularized means so as to lower the level of difficulty of platform construction. Meanwhile, 
when abnormity occurs to platform operation, a specific module can be rapidly located, and system can recover to normal operation after module modification and reloading so as to avoid its influence on the whole system.

\subsection{Module decomposition and definition}

During the process of module decomposition, divide model into two main types according to module's position in the system. The first type is front-end responsible for providing visual interface of system for users. The second type is back-end mainly responsible for implementing user's operation and transmitting operation result to the front end and sending feedback to users. Table 2 shows the module division details of the teaching platform and basic functions to be realized in each module.

Table 2. Module division table of multi-media teaching platform

\begin{tabular}{|l|l|l|}
\hline System position & \multicolumn{1}{|c|}{ Module name } & \multicolumn{1}{|c|}{ Basic function } \\
\hline & Front end basic module & $\begin{array}{l}\text { Implement system login, user management and other } \\
\text { basic functions }\end{array}$ \\
\hline Front end & $\begin{array}{l}\text { Excel display and operational } \\
\text { module }\end{array}$ & Provide Excel page display on webpages for students \\
\hline & VBA programming module & Provide VBA programming function for users \\
\hline Back end & Basic backend module & $\begin{array}{l}\text { Provide backstage service for login, user management } \\
\text { and other basic functions }\end{array}$ \\
\hline & $\begin{array}{l}\text { VBA and Java translation } \\
\text { module }\end{array}$ & \begin{tabular}{l} 
Implement the translation from VBA to Java \\
\hline
\end{tabular} \\
\hline & Excel operation module & $\begin{array}{l}\text { Provide function and interface encapsulation for Excel } \\
\text { operation through Java }\end{array}$ \\
\hline
\end{tabular}

\subsection{Module development}

After defining the functions of each system module, the paper has implemented module functions based on definitions and opened relevant interfaces to the external. First, the front-end basic module and basic back-end module provide basic service for multi-media teaching platform, and its development process is similar with ordinary application system development. This paper has applied JSP/Spring/MySQL integrated open-source framework to realize the development of these two basic functions. Secondly, for VBA and Java translation module, this article has translated VBA program code to Java program code with syntax tree as the medium. This module provides external interface with VBA program code as input and relevant Java program code segment as output. Thirdly, in Excel exhibition and development of operation module, this paper has packaged Excel basic operation based on POI software development kit issued by Apache Foundation according to the characteristics of platform operation on table cell and cell area in Excel file. The module has provided relevant interfaces for each function such as cell increasing, deleting, modifying and deleting function to the external, and it has also provided VBA programming function in 
webpage. This module will request relevant data processing and storage service from VBA, Java inter-translation module and Excel operation module.

\subsection{Module URL loading}

After completing functional module development, the whole system is completed after completing each module linkage and loading based on the framework of multimedia teaching platform. Fig 3 shows the system structure diagram of multi-media teaching platform. Three modules in front end page will request service from the back-end module after processing user's input. Then backend module will process backend database and Excel file relevantly based on user's input content, and after completion it will send results to frontend module and give feedback to user.

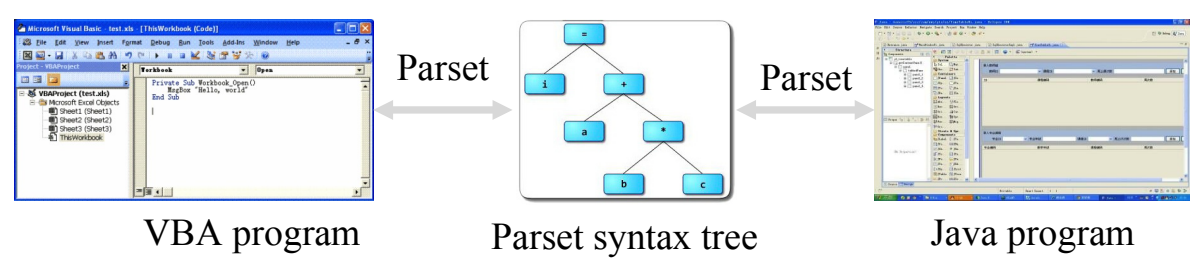

Fig. 3. System structure diagram of multi-media teaching platform

\subsection{Multi-media teaching platform display}

Display and elaborate the result of constructing multi-media teaching platform of Cost Accounting course based on Excel VBA program. The multi-media platform in this paper is constructed based on web development technology by using Apache Tomcat 7.0 version as its web server.

In the system login interface, user inputs user name, passwords and verification code shown on the page. Then user and passwords in the page will be encrypted and sent to backend for authentication. Then user can log into the system if authentication succeeds.

Fig 4 and 5 is the display page of multimedia teaching platform. After students log in the system, they can check the financial accounting related statement files. Meanwhile, after clicking the table cells in the form, students can check the basis and quoted date of cost allocation and accounting related to this cell. Meanwhile, results of students' operation on Excel after using VBA programing will show feedback in this page.

Each Excel display page has provided the interface button for VBA programming. Students can enter into the VBA programming window after clicking the button. After editing and submitting, the system can conduct syntax check on the students' input, and then transmit to the backstage for processing after no error detected. Results after processing will be show feedback to the system interface. Teacher-student interaction procedure displayed in multi-media teaching platform is as shown in Fig 6. 


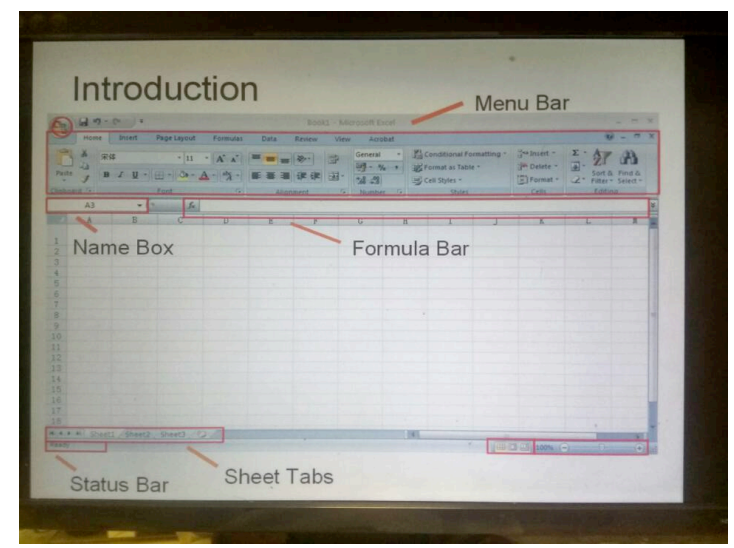

Fig. 4. Excel statement display page (1)

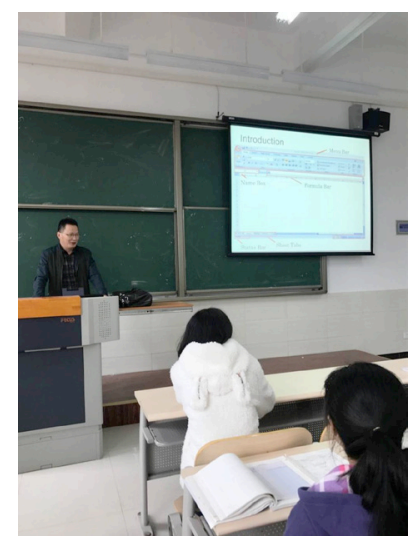

Fig. 5. Excel statement display page (2)

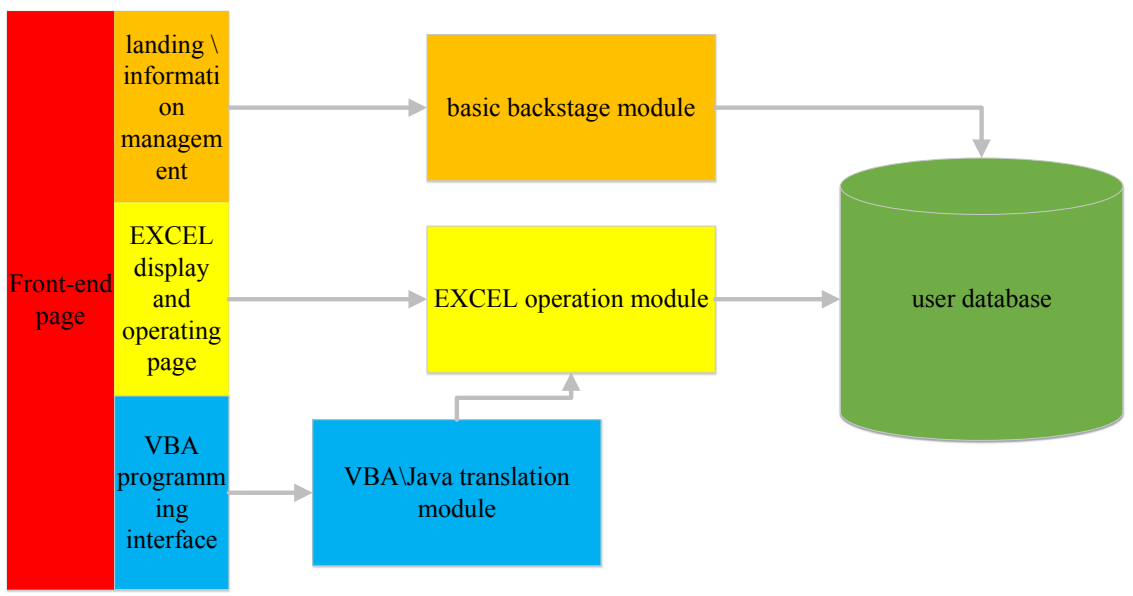

Fig. 6. Teacher-student interaction procedure display in multi-media teaching platform 


\subsection{Effect check}

After completing platform construction, to test the effect of platform in Cost Accounting course teaching, this platform was applied in practical teaching process by dividing students into two groups, experiment group and control group. The multimedia teaching platform is used in the experiment group and traditional teaching method is used in the control group with the same teaching materials used both. To uttermost reduce the influence of other factors, both groups receive the instruction of one teacher. Then test both groups with same quiz. Test results are shown in Table 3.

Table 3. Test score comparison between experiment group and control group

\begin{tabular}{|l|c|c|c|c|c|c|}
\hline \multirow{2}{*}{ Group } & \multirow{2}{*}{ Average score } & \multicolumn{5}{|c|}{ Student number in each score section } \\
\cline { 3 - 7 } & & Below 60 & $\mathbf{6 0 - 6 9}$ & $\mathbf{7 0 - 7 9}$ & $\mathbf{8 0 - 8 9}$ & $>\mathbf{9 0}$ \\
\hline Control group $(\mathrm{n}=50)$ & 86.4 & 0 & 4 & 16 & 23 & 7 \\
\hline Experiment group $(\mathrm{n}=50)$ & 81.2 & 2 & 7 & 23 & 15 & 3 \\
\hline
\end{tabular}

Meanwhile, a survey was conducted on platform teaching satisfaction among students by means of questionnaire. After completing course teaching and effect test, issue course satisfaction questionnaires to the experiment group including five questions, each in four dimensions. Questionnaire contents and survey results are shown in Table 4. It can be seen that $85 \%$ students think multi-media teaching platform constructed in this paper can effectively improve their understanding and application of Cost Accounting concepts. Also, more than $80 \%$ students think course teaching has effectively improved their practical ability and problem-solving ability which is a target of constructing the teaching platform. By applying this multi-media platform, students' satisfaction of teacher has improved.

Table 4. Survey results of experiment group students' satisfaction of teaching

\begin{tabular}{|c|c|c|c|c|c|}
\hline No. & Item & Very satisfaction & Satisfaction & Normal & Dissatisfaction \\
\hline 1 & $\begin{array}{l}\text { Concept understanding of Cost } \\
\text { Accounting }\end{array}$ & $36 \%$ & $52 \%$ & $8 \%$ & $4 \%$ \\
\hline 2 & $\begin{array}{l}\text { Knowledge application of Cost } \\
\text { Accounting }\end{array}$ & $42 \%$ & $48 \%$ & $2 \%$ & $2 \%$ \\
\hline 3 & Practical ability improving & $38 \%$ & $44 \%$ & $12 \%$ & $6 \%$ \\
\hline 4 & $\begin{array}{l}\text { Problem-solving ability improv- } \\
\text { ing }\end{array}$ & $40 \%$ & $48 \%$ & $4 \%$ & $8 \%$ \\
\hline 5 & Teachers satisfaction & $62 \%$ & $30 \%$ & $6 \%$ & $2 \%$ \\
\hline
\end{tabular}

\section{Conclusions}

This work has constructed a multi-media teaching platform for Cost Accounting course based on Excel VBA technology. Firstly, the paper analyzed the theoretical basis of multi-media teaching platform of Cost Accounting course from two aspects, 
VBA program design and Excel file remote operation. Then the paper presents the methods and procedures of constructing multi-media teaching platform based on Excel VBA, and the results. Finally, it applied and verified the effect of this teaching platform in practical teaching. Practice results show that the multi-media teaching platform constructed in this paper can significantly promote the teaching effect of Cost Accounting, and it is of great significance and value to improve students' practical ability and problem-solving ability. Compared with traditional teaching technologies, this multi-media technology has several advantages and values. Multi-media teaching technology based on Excel VBA can completely display data processing and calculation process in the class so that students can comprehensively understand the principle and process of data calculation. Using Excel VBA technology in classroom teaching can effectively improve students' Excel application ability and then improve their practical ability. In addition, the system can operate and process Excel through webpages while teachers are giving instruction. The technology has promoted a series of teaching reflection and improvement on the teaching model, students' course evaluation pattern, practical training system and learning method. It has also further enhanced the quality of accounting talent cultivation.

To sum up, combining VBA program design with Excel file remote operation can actively promote the teaching effect in accounting courses. This paper has conducted small-scale teaching with Cost Accounting course as an example.

\section{References}

[1] Luo, H.L., Shyu, M.L. Quality of service provision in mobile multimedia - a survey. Human-centric Computing and Information Sciences, 2011, vol. 1(1), pp. 5. https://doi.org/10.1186/2192-1962-1-5

[2] Ojala, T. Case studies on context-aware mobile multimedia services. Journal of Digital Information Management, 2010, vol. 8(1), pp. 4-15.

[3] Hoque, M.A., Siekkinen, M., Nurminen, J.K., et al. Mobile multimedia streaming techniques: QoE and energy saving perspective. Pervasive \& Mobile Computing, 2015, vol. 16, pp. 96-114. https://doi.org/10.1016/j.pmcj.2014.05.004

[4] Buchinger, S., Kriglstein, S., Brandt, S., et al. A survey on user studies and technical aspects of mobile multimedia applications. Entertainment Computing, 2011, vol. 2(3), pp. 175-190. https://doi.org/10.1016/j.entcom.2011.02.001

[5] Pattanaik, M. Design and Analysis of a Novel Low-Power SRAM Bit-Cell Structure at Deep-Sub-Micron CMOS Technology for Mobile Multimedia Applications. International Journal of Advanced Computer Science \& Application, 2011, vol. 2(2), pp. 43-49.

[6] Uluyol, C., Agca, R.K. Integrating mobile multimedia into textbooks: 2D barcodes. Computers \& Education, 2012, vol. 59(4), pp. 1192-1198. https://doi.org/10.1016/j.comp edu.2012.05.018

[7] Viana, W., Miron, A.D., Moisuc, B., et al. Towards the semantic and context-aware management of mobile multimedia. Multimedia Tools \& Applications, 2011, vol. 53(2), pp. 391-429. https://doi.org/10.1007/s11042-010-0502-6

[8] Su, Y.W. Design of multimedia electronic teaching map based on Flash+XML. China Educational Technology, 2011, vol. 32(3), pp. 127-130. 
Paper-Construction of the Multimedia Teaching Platform of Cost Accounting Course Based on ...

[9] Jiang, B. Construction of Characteristic Information Resource Repository in Mobile Digital Library. Journal of Library and Information Sciences in Agriculture, 2017, vol. 29(1), pp. 12-14.

[10] Zhang, Y.X. Some problems existing in the discipline construction of Ideological and Political Education. Ideological \& Theoretical Education, 2015, vol. 5, pp. 52-54.

[11] Bonk, C.J., Graham, C.R., Cross, J., et al. The Handbook of Blended Learning: Global Perspectives, Local Designs. Turkish Online Journal of Distance Education, 2009, vol. 10(4), pp. 181-181.

[12] Li, S., Cai, Z.Y. Research on and Application of Ruby on Rails Framework. Sci-Tech Information Development \& Economy, 2008, vol. 18(13), pp. 151-153.

\section{$7 \quad$ Author}

Zhiyong Zhang is an Associate Professor in Chongqing College of Finance and Economics, Chongqing 402160, China (zhangzhiyong1011@sina.cn).

Article submitted 13 February 2018. Resubmitted 18 March 2018. Final acceptance 25 March 2018. Final version published as submitted by the author. 